\title{
Interplay Between Toxoplasma gondii, Autophagy, and Autophagy Proteins
}

\author{
Carlos S. Subauste ${ }^{1,2 *}$ \\ 'Division of Infectious Diseases and HIV Medicine, Department of Medicine, Case Western Reserve University, Cleveland, \\ $\mathrm{OH}$, United States, ${ }^{2}$ Department of Pathology, Case Western Reserve University, Cleveland, $\mathrm{OH}$, United States
}

Survival of Toxoplasma gondii within host cells depends on its ability of reside in a vacuole that avoids lysosomal degradation and enables parasite replication. The interplay between immune-mediated responses that lead to either autophagy-driven lysosomal degradation or disruption of the vacuole and the strategies used by the parasite to avoid these responses are major determinants of the outcome of infection. This article provides an overview of this interplay with an emphasis on autophagy.

Keywords: autophagy, parasite, CD40, IFN-gamma, cell signaling

OPEN ACCESS

Edited by:

Jeroen P. J. Saeii,

University of California, Davis,

United States

Reviewed by:

Louis Weiss,

Albert Einstein College of Medicine, United States Eric Denkers,

University of New Mexico, United States

*Correspondence:

Carlos S. Subauste carlos.subauste@case.edu

Specialty section:

This article was submitted to

Parasite and Host,

a section of the journal

Frontiers in Cellular and Infection

Microbiology

Received: 26 February 2019 Accepted: 16 April 2019

Published: 01 May 2019

Citation:

Subauste CS (2019) Interplay

Between Toxoplasma gondii,

Autophagy, and Autophagy Proteins.

Front. Cell. Infect. Microbiol. 9:139.

doi: 10.3389/fcimb.2019.00139
Lysosomal degradation is an important mechanism of defense against numerous pathogens. This can be accomplished not only through the endocytic pathway but also through macroautophagy (called herein autophagy) (Levine et al., 2011). Autophagy is a homeostatic mechanism whereby large portions of cytosol or entire organelles are encircled by a double membrane (isolation membrane) leading to the formation of an autophagosome (Klionsky and Emr, 2000; Yoshimori, 2004; Mizushima et al., 2010). This structure fuses with lysosomes resulting in the formation of an autolysosome and cargo degradation (Mizushima et al., 2010).

Autophagy is dependent on a cascade of autophagy proteins (ATG). However, these proteins can have functions independent of autophagosome formation and lysosomal degradation (Subramani and Malhotra, 2013). This led to the use of the terms canonical and non-canonical autophagy where the latter was frequently used for processes that are non-degradative and/or not dependent on a core component(s) of the autophagy cascade [ATG3, ATG5, ATG7, Unc-51-like kinase 1 (ULK1), Beclin 1, and/or Phosphatidylinositol 3-kinase catalytic subunit type 3, PI3KC3, also known as VPS34] (Galluzzi et al., 2017). To avoid confusion, an expert panel recommended against the use of the terms "canonical"/"non-canonical," and advised that the term autophagy be used solely for processes dependent on autophagosomes where cytosolic material (either endogenous or exogenous) is directed to a process that culminates with and is strictly dependent on lysosomal degradation (Galluzzi et al., 2017). The processes can be further characterized by stating the autophagy proteins they are dependent on Galluzzi et al. (2017). In this review, we summarize studies on the interplay between T. gondii and host autophagy as well as non-degradative processes controlled by autophagy proteins.

\section{INVASION OF HOST CELLS BY T. GONDII}

Tachyzoites of $T$. gondii infect virtually any nucleated cell and survive by residing in a compartment called the parasitophorous vacuole (PV). This vacuole is formed during active invasion of host cells, a process dependent on the parasite actin-myosin motor and sequential secretion of proteins from micronemes and rhoptries (Bradley and Sibley, 2007; Besteiro et al., 2011; Santos and Soldati-Favre, 2011). Once secreted from micronemes, T. gondii micronemal proteins (MICs) are expressed 
on the parasite surface and function as adhesins that interact with host cell membrane receptors (Carruthers and Tomley, 2008). MICs are expressed as multiprotein complexes that include MIC1/4/6, MIC3/8, MIC2/M2AP, and a complex of the microneme protein TgAMA1 with rhoptry neck proteins (Cerede et al., 2005; Huynh and Carruthers, 2006; Sheiner et al., 2010). MICs contain domains such as type I thrombospondin repeats, apple domains, epidermal growth factor (EGF) repeats, and integrin A domains (Tomley and Soldati, 2001; Anantharaman et al., 2007). The connection between transmembrane MICs and the parasite actin-myosin motor together with binding to host cell receptors enables the parasite to penetrate host cells (Soldati-Favre, 2008; Sibley, 2011). Following the release of MICs, rhoptries secrete a complex of neck proteins (RONs) containing RON2 that associates with the host cell membrane, plus RON4, RON5, and RON8 that are exposed to the host cell cytoplasm (Bradley and Sibley, 2007; Besteiro et al., 2011; Santos and Soldati-Favre, 2011). The complex forms a structure called moving junction that anchors the parasite to the host cell cytoskeleton during invasion (Bradley and Sibley, 2007; Besteiro et al., 2011; Santos and Soldati-Favre, 2011). Tachyzoites penetrate the host cell through the moving junction causing invagination of the host cell membrane. The moving junction also appears to function as a sieve that excludes host type I transmembrane proteins from entering the membrane that encircles the parasite as it penetrates the host cell (Mordue et al., 1999; Besteiro et al., 2011). Once invasion is completed, T. gondii resides within the PV. While host endocytic structures are delivered intact into the vacuolar space, there is no release of endosomal contents into the vacuole (Coppens et al., 2006). The lack of fusion with the endocytic compartment would be explained by the absence of host type I transmembrane proteins in the PV membrane (PVM) (Mordue et al., 1999; Besteiro et al., 2011).

\section{AUTOPHAGY OVERVIEW}

Formation of the isolation membrane is dependent on recruitment of ATG proteins (Mizushima et al., 2010). Activation of both ULK1 and the complex that contains Beclin 1 and PI3KC3 drive the recruitment of ATG proteins to the isolation membrane promoting autophagosome formation and maturation (Chan et al., 2009; Itakura and Mizushima, 2010; Mizushima et al., 2010; Russell et al., 2013). ULK1 is the upstream kinase that triggers autophagy (Itakura and Mizushima, 2010). ULK1 is regulated by AMP-activated protein kinase (AMPK) and mechanistic target of rapamycin complex 1 (mTORC1), kinases that sense nutrient and energy status. In response to falling energy status, AMPK activates ULK1 and autophagy is stimulated (Chang et al., 2009; Egan et al., 2011; Kim et al., 2011; Mack et al., 2012). In contrast, ULK1 is inhibited by mTORC1 under nutrient rich conditions, leading to inhibition of autophagy (Chang et al., 2009). ULK1 undergoes membrane translocation upon activation by AMPK (Chang et al., 2009; Egan et al., 2011; Kim et al., 2011; Mack et al., 2012). Autophagosome biogenesis begins with the formation and activation of a ULK1-containing protein complex on membranes that express ATG9 (Papinski et al., 2014). ULK1 activates and recruits the Beclin 1-PI3KC3 complex to the membrane
(Itakura and Mizushima, 2010). PI3KC3 causes production of PI3P at the membrane (Liang et al., 1999) and recruitment of PI3P-binding proteins that would act as scaffold for proteins that mediate membrane remodeling (Nascimbeni et al., 2017). Active Beclin-PI3KC3 triggers recruitment of ATG proteins that in turn function as two ubiquitin-like conjugation systems. In one cascade, ATG7 and ATG10 promote the conjugation of ATG5 to ATG12 (Mizushima et al., 1998). In the other cascade, ATG3 and ATG7 together with the ATG12-ATG5-ATG16L1 complex allow lipidation (phosphatidylethanolamide conjugation) of LC3 (ATG8) (Mizushima et al., 1998). Lipidated LC3 (LC3-II) is recruited to the autophagosome membrane (Kabeya et al., 2000) and allows substrate uptake by binding to several autophagy receptors (Stolz et al., 2014; Wild et al., 2014). Once the cargo is sequestered by the autophagosomes and through the effect of proteins that include Rab7 (Gutierrez et al., 2004), these structures fuse with lysosomes leading to the formation of an autolysosome.

Beclin 1 is regulated through protein-protein interactions. Beclin 1 binds proteins that promote autophagy (e.g., ATG14L) whereas binding to other proteins (e.g., Bcl-2 family members) inhibits autophagy (Pattingre et al., 2005; Sun et al., 2008; Matsunaga et al., 2009). Under basal conditions Bcl-2 binds to the $\mathrm{BH} 3$ domain of Beclin 1 preventing the association of Beclin 1 to PI3KC3 and the initiation of autophagy (Pattingre et al., 2005). Starvation stimulates autophagy in part because it triggers JNK1dependent phosphorylation of Bcl-2 that releases Beclin 1 from Bcl-2 (Wei et al., 2008).

Autophagy proteins can be involved in cellular processes activated during intracellular infections that do not represent bona fide autophagy. LC3-associated phagocytosis (LAP) represents an example of such a process. LAP consists in the recruitment of LC3 and some other components of the autophagy pathway to single-membrane phagosomes that contain pathogens or dead cells that have been actively phagocytosed (Sanjuan et al., 2007). While LAP requires proteins that include ATG3, ATG5, ATG7, ATG12, ATG16L, Beclin 1, and PI3KC3, other proteins notably ULK1 are not involved in this process (Martinez et al., 2015). LAP is believed to result in faster fusion with lysosomes and plays a protective role against various pathogens (Sanjuan et al., 2007; Martinez et al., 2015). Autophagy proteins can be involved in additional mechanisms of anti-microbial activity that occur independently of the formation of autophagosomes and are not mediated by lysosomal degradation of the pathogen. In this regard, IFN- $\gamma$ induces autophagy protein-dependent recruitment of GTPases that disrupt the integrity of the PV membrane (see below).

\section{AUTOPHAGY DURING T. GONDII INFECTION \\ CD40 Stimulates Autophagy and Triggers Autophagic Targeting of $T$. gondii}

Autophagy can be stimulated by innate and adaptive immune mechanisms to degrade various pathogens (Levine et al., 2011). Pattern recognition receptors including TLR and NOD2 as well as cytokines such IFN- $\gamma$ and type I interferon can 
stimulate autophagy (Shi and Kehrl, 2010; Gade et al., 2012; Matsuzawa et al., 2012; Chauhan et al., 2015). CD40 is a stimulator of autophagy that confers resistance against cerebral and ocular toxoplasmosis. CD40 is a member of the TNF receptor superfamily that is expressed on antigen presenting cells and various non-hematopoietic cells (Van Kooten and Banchereau, 2000). CD40 ligand (CD154) is expressed primarily on activated $\mathrm{CD} 4^{+} \mathrm{T}$ cells but is also present in activated platelets and plasma (Van Kooten and Banchereau, 2000). Studies in patients with congenital lack of functional CD154 (X-linked Hyper IgM syndrome) uncovered the central role of the CD40CD154 pathway in protection against toxoplasmosis (Subauste et al., 1999). While the CD40-CD154 pathway promotes Th1type cytokine response against T. gondii (Subauste et al., 1999; Reichmann et al., 2000), toxoplasmacidal activity induced by CD40 ligation in infected cells likely contributes to protection against the parasite (Reichmann et al., 2000; Portillo et al., 2010). Using peritoneal cells from T. gondii-infected mice, it has been proposed that CD40 plays a secondary role in parasite elimination in macrophages, although the $\mathrm{CD} 4^{+} \mathrm{T}$ cellmacrophage ratio (extent of CD40-CD154 interaction in vitro) and whether macrophages infected in vitro had undergone prior CD40-CD154 signaling in vivo were unclear (Zhao et al., 2007). Other studies demonstrated that $\mathrm{CD}_{154^{+}} T$. gondii-reactive $\mathrm{CD}^{+}{ }^{+} \mathrm{T}$ cells induce anti-T. gondii activity in macrophages even if CD40 ligation occurs in cells already infected with $T$. gondii (Andrade et al., 2006). Importantly, studies in CD154-/and $\mathrm{CD} 40^{-/}$mice established that this pathway is central for restricting parasite load in the brain and retina, and protecting against cerebral and ocular toxoplasmosis (Reichmann et al., 2000; Portillo et al., 2010), the two main forms of disease in humans.

Several lines of evidence indicate that CD40 stimulates autophagy and induces killing of $T$. gondii through autophagic targeting of the parasite, a phenomenon that occurs in hematopoietic and non-hematopoietic cells from both human and mice. CD40 ligation increases conversion of the autophagy protein LC3-I to LC3-II, as well as increases formation of autophagosomes and autolysosomes (autophagy flux). These events are dependent on ULK1, ATG5, ATG7, and Beclin 1 (Andrade et al., 2006; Portillo et al., 2010; Ogolla et al., 2013; Van Grol et al., 2013; Liu et al., 2015). In cells infected with T. gondii, CD40 ligation induces accumulation of mannose 6 phosphate receptor, Rab7, LAMP-1, LAMP-2, CD63, and cathepsin D around the PV as well as co-localization of these vacuoles with the acidotropic dye Lysotracker (Andrade et al., 2006; Portillo et al., 2010; Ogolla et al., 2013; Van Grol et al., 2013). Accumulation of lysosomal markers occurs around vacuoles that contain proteins secreted by parasite dense granules within the vacuolar lumen (Andrade et al., 2006). This indicates that the events triggered by CD40 represent fusion of the PV with lysosomes rather than being a consequence of phagocytosis since secretion of dense granule contents takes place during formation of PV but not during phagocytosis of T. gondii. Moreover, vacuolelysosomal fusion (VLF) still occurs even if CD40 is engaged $18 \mathrm{~h}$ after infection (Andrade et al., 2006). VLF is preceded by accumulation of LC3 around the PV. Autophagy mediates VLF and killing of $T$. gondii since knockdown of ULK1, Beclin 1, PI3KC3, ATG5, or ATG7, expression of dominant negative Rab7 or pharmacologic inhibition of vacuolar ATPase or PI3K, and importantly incubation with lysosomal enzyme inhibitors ablate killing of T. gondii induced by CD40 (Andrade et al., 2006; Portillo et al., 2010; Van Grol et al., 2013). CD40 triggers VLF via autophagy rather than LAP since ULK1 is required for autophagy while LAP takes place independently of ULK1 (Martinez et al., 2015). In addition, the events triggered by CD40 ligation do not represent phagocytosis of the parasite.

CD40 stimulates autophagy via four mechanisms (Figure 1). First, CD40 induces CaMKK $\beta$-mediated Threonine-172 AMPK phosphorylation, a marker of AMPK activation (Liu et al., 2016). In turn, AMPK signaling causes Serine-555 ULK1 phosphorylation and ULK1-mediated autophagy (Liu et al., 2016). Second, CD40 induces autocrine secretion of TNF- $\alpha$ that causes JNK1/2-dependent phosphorylation of Bcl-2 at Serine 87 and dissociation of Bcl-2 from Beclin 1 (Subauste et al., 2007; Liu et al., 2016). The latter process is known to allow binding of Beclin 1 to PI3KC3 and initiation of autophagy (Pattingre et al., 2005). Third, CD40 upregulates Beclin 1 protein levels in vitro and in vivo (Portillo et al., 2010). This effect appears to occur through downregulation of $\mathrm{p} 21$, a protein that degrades Beclin 1 (Portillo et al., 2010). Consistent with the evidence that the level of Beclin 1 expression is linked to autophagic activity (Liang et al., 1999), CD40-induced Beclin 1 upregulation facilitates autophagic killing of $T$. gondii triggered by CD40 (Portillo et al., 2010). These three events act in synchrony, likely optimizing the ability of CD40 to stimulate autophagy and induce toxoplasmacidal activity. Finally, CD40 also promotes autophagy by activating PKR (Ogolla et al., 2013), a serine-threonine kinase that stimulates autophagy (Talloczy et al., 2002, 2006). These events are relevant to $T$. gondii since autophagic targeting and/or killing of the parasite induced by CD40 is dependent on CaMKK $\beta$, AMPK, TNF- $\alpha$, JNK1/2, Beclin 1 upregulation, p21 downregulation, and PKR (Subauste et al., 2007; Portillo et al., 2010; Ogolla et al., 2013; Liu et al., 2016).

Animal studies support the importance of autophagy for control of T. gondii in the brain and eye. Autophagy-deficient $B E C N 1^{+/-}$mice, mice with deficiency of the autophagy protein ATG7 targeted to microglia/macrophages (Atg $7^{\text {flox } / \text { flox }}$-Lyz-M Cre mice) and $\mathrm{PKR}^{-/-}$mice are susceptible to cerebral and ocular toxoplasmosis (Portillo et al., 2010; Ogolla et al., 2013). This susceptibility is not explained by defects in cellular or humoral immunity against the parasite. Moreover, macrophages/microglia from these mice exhibit impaired killing of $T$. gondii in response to CD40 but not IFN $-\gamma$ stimulation (Portillo et al., 2010; Ogolla et al., 2013).

\section{T. gondii Manipulates Host Cell Signaling to Avoid Targeting by Autophagy}

Avoidance of the lysosomal compartment is essential for T. gondii survival. Autophagy is a constitutive process in eukaryotic cells. Moreover, a fraction of host cells is unable to exhibit autophagic targeting and VLF of intracellular tachyzoites despite activation through CD40. These findings suggest that T. gondii 


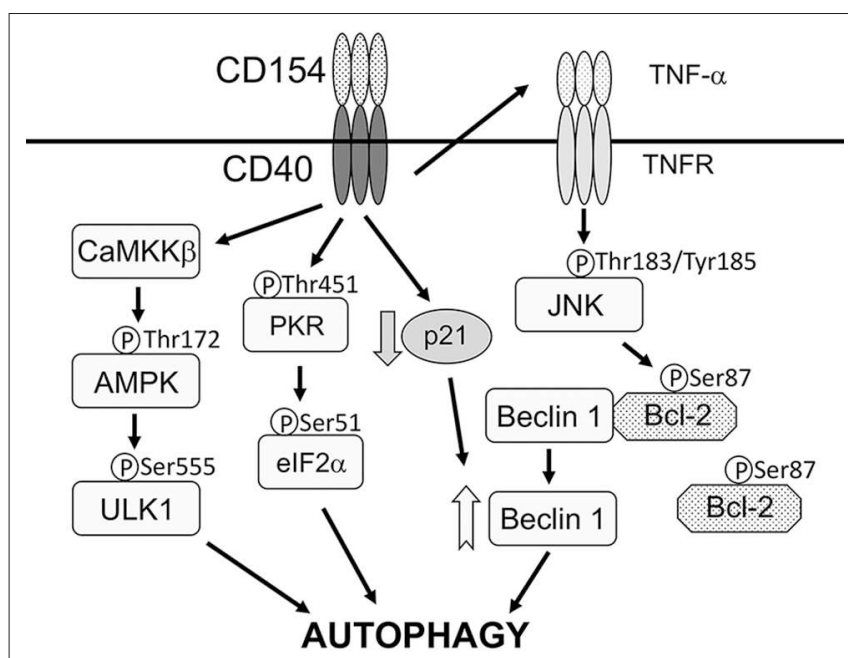

FIGURE 1 | CD40 activates signaling pathways that stimulate autophagy. CD40 stimulates autophagy via four mechanisms. (1), CD40 induces CaMKK $\beta$-mediated Threonine-172 AMPK phosphorylation that in turn causes Serine-555 ULK1 phosphorylation and ULK1-mediated autophagy. (2), CD40 induces autocrine secretion of TNF- $\alpha$ that causes JNK1/2-dependent phosphorylation of Bcl-2 at Serine 87 and dissociation of Bcl-2 from Beclin 1. (3), CD40 upregulates Beclin 1 protein levels likely through downregulation of p21. (4), CD40 activates PKR and elF2 $\alpha$. CD40 may activate additional mechanisms that act on ULK1 and Beclin 1. CD40 causes autophagic killing of T. gondii that is dependent on ULK1, Beclin 1, PI3KC3, ATG5, ATG7, and lysosomal enzymes. Modified with permission from Liu et al. (2016).

uses strategies to avoid targeting by autophagosomes. Indeed, the parasite activates host cell signaling pathways that achieve this purpose.

Epidermal growth factor receptor (EGFR) is expressed in various cells various cell types (including epithelial cells, endothelial cells, microglia, and certain neurons) and can inhibit autophagy (Sobolewska et al., 2009). EGFR is composed of extracellular (ligand binding), transmembrane, intracellular tyrosine kinase and carboxyl-terminal tail domains (Purba et al., 2017). Ligand binding causes a conformational change in the kinase domain leading to activation of EGFR through autophosphorylation of tyrosine residues in the carboxylterminal tail (Purba et al., 2017). These phosphorylated residues recruit signaling molecules downstream of EGFR (Purba et al., 2017). T. gondii induces phosphorylation of the tyrosine residues $1,068,1,148$, and 1,173 of EGFR during infection of human or rodent cells (Muniz-Feliciano et al., 2013). T. gondiiinduced EGFR signaling leads to activation of PI3K (MunizFeliciano et al., 2013), a molecule that triggers production of phosphatidylinositol 3,4,5 trisphosphate (PIP3). Transfection of host cells with a plasmid encoding GFP-tagged amino-terminal pleckstrin homology $(\mathrm{PH})$ domain of Akt that binds PIP3 revealed PIP3 accumulation around the PV (Muniz-Feliciano et al., 2013). Consistent with the fact that PIP3 production is a major trigger of Akt activation, T. gondii induces Akt activation (Muniz-Feliciano et al., 2013) (Figure 2A). While parasite-induced Akt activation in macrophages is impaired by Pertussis Toxin (PTx) suggesting that Akt signaling can be dependent on G-protein coupled receptors (GPCR) (Kim and
Denkers, 2006), genetic and pharmacologic blockade of EGFR in various cell types including macrophages/microglia revealed that EGFR is an important driver of Akt activation triggered by T. gondii (Muniz-Feliciano et al., 2013).

Inhibition of the EGF $\rightarrow$ Akt pathway results in spontaneous recruitment of LC3 and formation of a double membrane structure around the PVM followed by VLF (Muniz-Feliciano et al., 2013). In both human and mouse cells, ensuing killing of type I and II strains of T. gondii is dependent on ULK1, Beclin 1, ATG7, and lysosomal enzymes (Muniz-Feliciano et al., 2013). These results are likely explained by the fact that Akt is a negative regulator of autophagy via activation of mTORC1 (Menon et al., 2014). Given that Akt activation is linked to inhibition of apoptosis of T. gondii-infected cells (Kim and Denkers, 2006), parasite-induced EGFR-Akt signaling may promote parasite survival by preserving the non-fusogenic nature of the PV and by avoiding death of infected cells subjected to pro-apoptotic signals.

EGFR can be activated by transmembrane proteins that are shed from the plasma membrane as a consequence of the ADAM (a disintegrin and metalloprotease) family of zinc-dependent metalloproteases (Yarden and Sliwkowski, 2001). This process is stimulated by GPCR (Yarden and Sliwkowski, 2001). However, treatment with GM6001, a broad-spectrum ADAM inhibitor, or with PTx fails to inhibit T. gondii-induced EGFR activation (Muniz-Feliciano et al., 2013). The parasite causes EGFR phosphorylation at tyrosine 1,148 (Muniz-Feliciano et al., 2013), a site that appears to be phosphorylated only by ligand binding to EGFR (Moro et al., 2002). In this regard, MIC3, MIC6, MIC8 have multiple domains with homology to EGF (Meissner et al., 2002). Recombinant MIC3 and MIC6 but not MIC4 or M2AP induce EGFR-Akt signaling in mammalian cells and impair the ability of CD154 to induce LC3 accumulation around the parasite (Muniz-Feliciano et al., 2013). In addition, MIC1 ko (deficient in MIC6), MIC3 ko and especially MIC1/3 ko parasites are defective in induction of EGFR-Akt activation (Muniz-Feliciano et al., 2013). While cells infected with MIC1/3 ko T. gondii do not exhibit spontaneous targeting by $\mathrm{LC}^{+}$structures, there is increased recruitment of LC3 and susceptibility to killing after incubation with stimulators of autophagy (CD154, Rapamycin) (Muniz-Feliciano et al., 2013). The likely explanation for these results is that $\mathrm{MIC1} / 3$ ko $T$. gondii have residual ability to induce EGFR-Akt signaling (Muniz-Feliciano et al., 2013). Although MIC8 has EGF-like domains, MIC8 ko parasites show no defect in EGFR activation (Muniz-Feliciano et al., 2013). These findings are likely explained by the fact that MIC8 ko parasites are not defective in host cell attachment and secrete MICs (Kessler et al., 2008). Whether simultaneous deficiency in MIC3, MIC6 and MIC8 ablates EGFR autophosphorylation or whether there is another mechanism that contributes to EGFR autophosphorylation remains to be determined. Taken together, in addition to being key for invasion of host cells, these studies indicate that MIC3 and MIC6 promote EGFR-Akt signaling to avoid lysosomal degradation of the parasite (Figure 2A).

Another mechanism operative in both human and murine cells that enables type I, II, and atypical strains of T. gondii to avoid targeting by autophagosomes is dependent on activation 


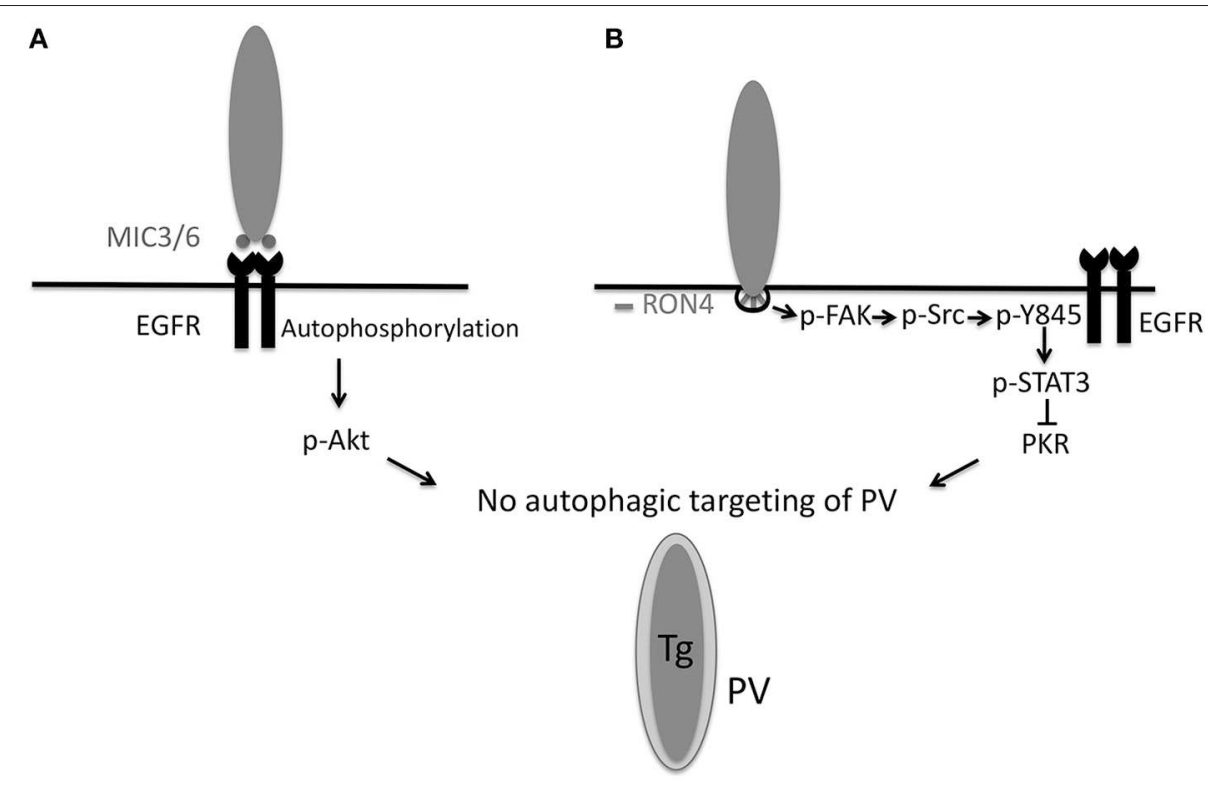

FIGURE 2 | T. gondii invasion of host cells activates signaling cascades that prevent autophagic targeting of the parasite. (A) During attachment to host cells, T. gondii MIC3 and MIC6 cause EGFR autophosphorylation, leading to PI3K-dependent activation of Akt. Blockade of EGFR, PI3K, or Akt leads to autophagic targeting of the PV and killing of the parasite. (B) During invasion of host cells, the formation of the moving junction, characterized by expression of RON4, is accompanied by activation of FAK. In turn, FAK activates Src causing Src-dependent transactivation of EGFR (Y845 phosphorylation). This unique form of EGFR activation recruits STAT3 signaling that prevents activation of PKR and elF2 $\alpha$. Blockade of the signaling cascade results in activation of PKR and elF2 $\alpha$ leading to autophagic targeting and killing of the parasite. Inhibition of the MIC3/6 $\rightarrow$ EGFR $\rightarrow$ Akt or the FAK $\rightarrow$ SrC $\rightarrow$ pY845 EGFR $\rightarrow$ STAT3 pathways results in autophagic killing of $T$. gondii that is dependent on ULK1, Beclin 1, ATG7, and lysosomal enzymes. Modified with permission from Portillo et al. (2017) PLoS Pathog 13, e1006671.

of Focal Adhesion Kinase (FAK), a cytoplasmic molecule that links extracellular signals to intracellular signaling cascades. $T$. gondii induces FAK activation at the level of the moving junction, an effect that is largely mediated by $\beta$ integrins, presumably in the form of mechano-transduction-induced integrin clustering at the site of penetration of host cells (Portillo et al., 2017) (Figure 2B). Src becomes activated as a consequence of T. gondiiinduced FAK activation (Portillo et al., 2017). Src can bind EGFR and transactivate this receptor even in the absence of ligand binding (Biscardi et al., 1999). EGFR transactivation is characterized by phosphorylation of a unique tyrosine 845 in the kinase domain of EGFR that recruits alternate signaling cascades downstream of EGFR including STAT3. Indeed, T. gondii triggers Src dependent phosphorylation of tyrosine 845 of EGFR followed by activation of STAT3 (Portillo et al., 2017) (Figure 2B), a negative regulator of autophagy (Van Grol et al., 2010; Shen et al., 2012). In the case of T. gondii infection, STAT3 activation prevents autophagic targeting of the parasite by impairing activation of the pro-autophagy protein PKR and its downstream signaling molecule eIF2 $\alpha$ (Portillo et al., 2017). Genetic or pharmacologic blockade of any component of the FAK $\rightarrow$ Src $\rightarrow$ p 845Y EGFR $\rightarrow$ STAT3 pathway causes recruitment of LC3 around the parasite, VLF and parasite killing dependent on ULK1, Beclin 1, and lysosomal enzymes (Portillo et al., 2017). Thus, T. gondii activates an Akt- and a STAT3-dependent signaling pathway in both human and mouse cells to avoid autophagic targeting, and these pathways appear to function independently (Portillo et al., 2017) (Figure 2).
Animal studies have recently demonstrated the in vivo relevance of $T$. gondii-induced manipulation of host cell signaling in the pathogenesis of cerebral and ocular toxoplasmosis. The CNS is invaded via the blood stream when tachyzoites present in circulating infected leukocytes or extracellular tachyzoites reach the brain (Courret et al., 2006; Konradt et al., 2016). CNS invasion is preceded by infection of endothelial cells (Konradt et al., 2016). Expression of a dominant negative EGFR in endothelial cells ablates T. gondii-induced autophosphorylation and transactivation of EGFR (Lopez Corcino et al., 2019). Transgenic mice whose endothelial cells express DN EGFR exhibit diminished parasite load and histopathology in the brain and retina after T. gondii infection (Lopez Corcino et al., 2019). Mice with DN EGFR have reduced parasite load in these organs after i.v. administration of infected leukocytes or extracellular tachyzoites (Lopez Corcino et al., 2019). This protective effect is not explained by enhanced immunity or reduced leukocyte recruitment into the CNS. Rather, the effect of DN EGFR is to reduce the foci of infection in neural endothelial cells (Lopez Corcino et al., 2019). DN EGFR in these cells results in the spontaneous recruitment of LC3 around T. gondii, VLF and parasite killing dependent on ULK1 and lysosomal enzymes (Lopez Corcino et al., 2019). Moreover, in vivo administration of autophagy inhibitor 3methyl adenine prevents DN EGFR mice from exhibiting reduced CNS invasion (Lopez Corcino et al., 2019). Altogether, EGFR is a novel regulator of $T$. gondii invasion of neural tissue, enhancing invasion likely by promoting survival of 
the parasite within endothelial cells through avoidance of autophagic targeting.

Although $T$. gondii activates signaling molecules that can inhibit autophagy, T. gondii does not prevent autophagosome formation in infected cells (Wang et al., 2009). In fact, T. gondii increases LC3-II levels and autophagosome formation in host cells at $24 \mathrm{~h}$ post-infection (Wang et al., 2009). These studies together with the demonstration that $T$. gondii induces lipophagy in host cells to obtain fatty acids (Pernas et al., 2018) would support that the parasite co-opts host cell autophagy to gain access to nutrients for its growth (Wang et al., 2009; Pernas et al., 2018). A model has been proposed whereby T. gondii utilizes the autophagy machinery of permissive (non-activated) host cells for its own benefit, whereas host cell autophagy would lead to parasite killing only in immune-activated host cells (Latre De Late et al., 2017). However, the signaling studies described above revealed an additional layer of complexity. They begin to indicate that CD40 and T. gondii have opposing effects on signaling molecules that regulate autophagy (i.e., PKR). The balance between these opposing effects may determine whether autophagic targeting of the parasite takes place. Host cell autophagy would cause parasite killing not only in CD40activated host cells but also in resting cells if the effects of T. gondii on EGFR $\rightarrow$ Akt or FAK/Src $\rightarrow$ p-Y845 EGFR $\rightarrow$ STAT3 signaling are blocked. This model has therapeutic implications since, for example, addition of EGFR tyrosine kinase inhibitors to resting cells restricts $T$. gondii growth (Muniz-Feliciano et al., 2013; Yang et al., 2014). Host cell autophagy would be beneficial to the parasite in resting host cells as long as the parasite is able to activate negative regulators that prevent autophagosomes from targeting and killing the parasite. In these cells, activation of the regulatory signaling cascades would not appear to inhibit global autophagy but rather would impair targeting of the parasite by autophagosomes.

\section{AUTOPHAGY-INDEPENDENT EFFECTS OF AUTOPHAGY PROTEINS DURING T. GONDII INFECTION}

\section{IFN- $\gamma$ Restricts T. gondii Through Autophagy-Independent Effects of Autophagy Proteins}

IFN- $\gamma$ is a major activator of effector responses against $T$. gondii in mammalian cells. IFN- $\gamma$ causes vesiculation and rupture of the PVM in mouse cells leading to parasite release into the cytoplasm and parasite death (Martens et al., 2005; Zhao et al., 2008, 2009). While autophagosome-like structures can be noted around the parasites (Ling et al., 2006), the function of these structures is not to kill the parasite but likely to clear parasite/PVM fragments (Zhao et al., 2008; Choi et al., 2014; Ohshima et al., 2014). Indeed, parasite killing in IFN- $\gamma$-activated mouse cells is not mediated by lysosomal activity since expression of DN Rab7 that would inhibit lysosomal fusion and/or autolysosome maturation (Andrade et al., 2006) or incubation with lysosomal protease inhibitors fail to impair the anti- $T$. gondii activity induced by IFN- $\gamma$ (Andrade et al., 2006; Van Grol et al., 2013; Choi et al.,
2014). Thus, bona fide autophagy does not mediate the anti-T. gondii effects of IFN- $\gamma$.

Interestingly, while autophagosomes are not involved in killing of susceptible strains of $T$. gondii within IFN- $\gamma$-activated cells (Zhao et al., 2008), selected autophagy proteins are required for parasite death in mouse cells. These autophagy proteins function by promoting recruitment of Immunity Regulated GTPases (IRGs) and Guanylate Binding Proteins (GBPs) to the PVM (Figure 3A). IFN- $\gamma$ induces recruitment and loading of effector GKS subfamily of IRGs (Irga6, Irgb6, Irgb10, Irgd) onto the PVM causing its disruption (Martens et al., 2005; Ling et al., 2006; Khaminets et al., 2010). IRGs promote ubiquitin deposition on the PVM followed by p62-dependent recruitment of GBPs (Haldar et al., 2015) (Figure 3A). Disruption of the PVM enables GBPs to bind and kill the parasite (Kravets et al., 2016). ATG5 is required for recruitment of GKS IRGs (Irga6, Irgb6, Irgd) and mGBP1 to the PVM in IFN- $\gamma$-activated mouse macrophages and fibroblasts (Zhao et al., 2008; Khaminets et al., 2010; Selleck et al., 2013). Similarly, ATG7 and ATG16L1 are necessary for Irgb6 and mGBP1-5 recruitment (Choi et al., 2014; Ohshima et al., 2014) while ATG3 is required for recruitment of Irgb6, Irb10 and mGBP1-5 in fibroblasts (Choi et al., 2014; Haldar et al., 2014). Consistent with the fact that ATG3, ATG7, and the ATG12-ATG5-ATG16L1 complex mediate LC3 conjugation, LC3 is recruited to the PVM in IFN- $\gamma$-activated mouse macrophages and fibroblasts (Choi et al., 2014; Park et al., 2016). The LC3 homologs gamma-aminobutyric acid-Areceptor-associated proteins (GABARAPs) are also recruited to the PVM in a conjugation-dependent manner (Park et al., 2016). These proteins target IRGs to the PVM in mouse cells (Park et al., 2016). In another study, GABARAPL2 (Gate-16) but not LC3 was required for recruitment of Irga6 and GBP1-5 to the vacuole of IFN- $\gamma$-treated mouse fibroblasts (Sasai et al., 2017).

As stated above, ATG proteins do not function through bona fide autophagy to restrict $T$. gondii in IFN- $\gamma$ activated cells. Indeed, lysosomal degradation does not mediate the effects of these proteins (Choi et al., 2014). Moreover, ULK1 and ATG14L are not required in order for IFN- $\gamma$ to control T. gondii (Choi et al., 2014). Similarly, ATG9, ATG14L and FIP200 are not required for recruitment of LC3, Irg6a and GBP to the vacuole (Choi et al., 2014; Ohshima et al., 2014; Sasai et al., 2017). While the mechanism of action of ATG proteins remains to be fully elucidated, these proteins may activate IRGs (Haldar et al., 2014), LC3 may target IRGs to the membrane (Park et al., 2016), and Gate-16 associates with the small GTPase ADP-ribosylation factor 1 (Arf1) to mediate IRG recruitment (Sasai et al., 2017).

IRGs represent the major mechanism by which IFN- $\gamma$ protects mice during the acute phase of $T$. gondii infection (Martens et al., 2005). Consequently, ATG proteins not only mediate the anti- $T$. gondii activity in mouse cells activated by IFN- $\gamma$ but they are also required for in vivo protection. Mice with deficiency in ATG5, ATG7, or ATG16L targeted to phagocytes exhibit marked susceptibility to acute infection with T. gondii (Zhao et al., 2008; Choi et al., 2014). In contrast, ATG14L deficiency does not increase susceptibility to acute infection (Choi et al., 2014). In addition, Gate-16 $16^{-/}$mice succumb to 
A

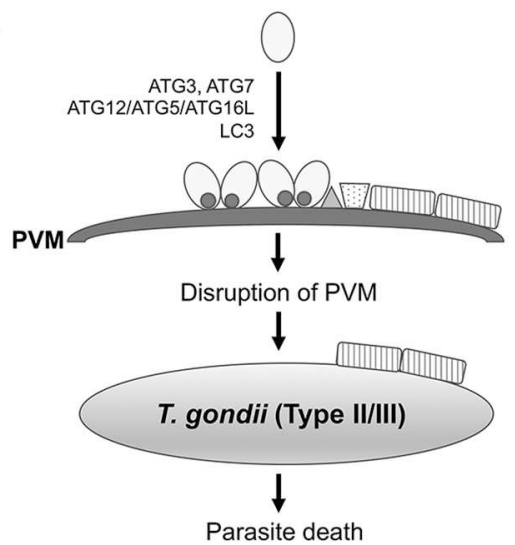

B

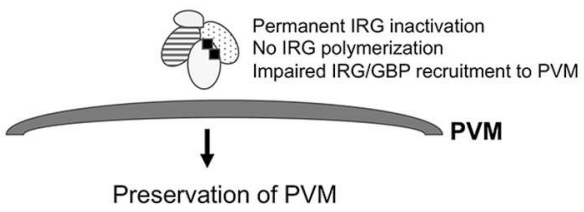

Preservation of PVM

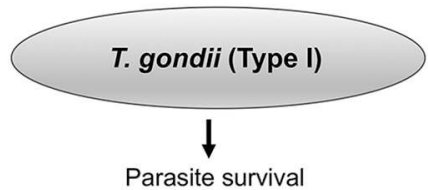

\begin{tabular}{|c|c|c|c|}
\hline \multirow{3}{*}{0} & GKS IRG & $\triangle$ ubiquitin & ROP18 \\
\hline & GTP & p62 & ROP5 \\
\hline & p-Threonine & \|\| GBP & GRA7 \\
\hline
\end{tabular}

FIGURE 3 | IFN- $\gamma$-induced recruitment of IRG and GBP to the PVM in mouse cells leads to killing of $T$. gondii, an effect that is prevented by virulent strains of the parasite. (A) IFN- $\gamma$ induces expression of IRGs and GBPs in mouse cells. In cells infected with type II or III strains of $T$. gondii, IFN- $\gamma$ causes recruitment of GKS IRGs to the PVM, an effect that is mediated by ATG3, ATG7, ATG12-ATG5-ATG16L, and LC3. IRGs drive ubiquitin deposition and p62-mediated recruitment of GBP to the PVM. IRGs and GBP disrupt PVM enabling GBPs to bind the surface membrane of the parasite leading to parasite death. (B) In mouse cells infected with type I $T$. gondii, ROP5/ROP18/GRA7 form a complex with IRG causing threonine phosphorylation. As a result, IRGs remain in an inactive GDP-bound conformation that prevents their oligomerization and loading into the PVM. ROP17 also phosphorylates threonine residues of IRG (see text). The models shown represent events that take place in mouse cells. Mechanisms operative in human cells are described in the text.

acute infection with T. gondii in a manner that mimics IFN- $\gamma^{-/-}$ mice (Sasai et al., 2017).

The effector mechanisms activated by IFN- $\gamma$ to restrict $T$. gondii growth in human cells are less well-characterized and differ from those in mouse cells. Mechanisms in human cells appear to be cell-type specific and are reported to include induction of indoleamine 2,3-dioxygenase that deprives the parasite from tryptophan (Pfefferkorn, 1984) and host cell death that results in early parasite egress without replication (Niedelman et al., 2013). In contrast to mice, humans express only 2 IRGs that cannot be induced by IFN- $\gamma$ explaining why IRGs do not mediate the effects of IFN- $\gamma$ in human cells (Bekpen et al., 2005). Human cells express GBPs (Ohshima et al., 2014). Moreover, hGBP1-5 are recruited to the parasite in an ATG16L-dependent manner in IFN- $\gamma$-activated human HAP1 cells (Ohshima et al., 2014). However, GBPs are not required for restriction of $T$. gondii (Ohshima et al., 2014). Studies in human epithelial (HeLa) cells identified a mechanism for control of type II and type III T. gondii induced by IFN- $\gamma$ that is dependent on ubiquitination and some ATG proteins (Selleck et al., 2015). IFN- $\gamma$ induces ubiquitination of the PV and recruitment of the ubiquitin adaptor proteins p62 and Nuclear Domain 10 Protein 52 (NDP52), as well as LC3 (Selleck et al., 2015). These vacuoles become surrounded by multiple layers of host membrane that would restrict parasite growth (Selleck et al., 2015). While this process is dependent on ATG16L and ATG7, it occurs independently of Beclin 1 and does not cause VLF, indicating that it does not represent autophagy (Selleck et al., 2015).
IFN- $\gamma$ was reported to restrict $T$. gondii growth within human endothelial cells through a mechanism that remained to be identified (Woodman et al., 1991). A recent study revealed that vacuoles containing type II T. gondii within human endothelial cells are targeted by K63-linked ubiquitin in response to IFN$\gamma$ (Clough et al., 2016). This is followed by recruitment of p62 and NDP52, acidification of the vacuole and parasite death. This process does not represent autophagy since it is not accompanied by recruitment of ATG16L, GABARAP, and LC3 (Clough et al., 2016). Moreover, in contrast to IFN- $\gamma$-activated HeLa cells, the ability of IFN- $\gamma$ to restrict parasite growth in human endothelial cells is not dependent on ATG16L (Clough et al., 2016). Taken together, there are two novel cell-type specific mechanisms by which IFN- $\gamma$ restricts the parasite growth in human nonhematopoietic cells. These mechanisms involve ubiquitination of the vacuole followed by either the formation of a multilayer structure around the vacuole or vacuole acidification.

\section{T. gondii Impairs Recruitment of IRGs to the PVM}

The ability of IRGs to protect mice against T. gondii depends on the parasite strain. While virulent type I T. gondii prevents recruitment of IRGs to the PVM and avoids eradication, low virulence type II strains and avirulent type III strains of T. gondii cannot avoid IRG recruitment and are thus eradicated (Zhao et al., 2009; Khaminets et al., 2010). Evasion of IRG recruitment is mediated by parasite proteins released within host cells during invasion. The rhoptry protein ROP18 is a polymorphic protein kinase and a major determinant of parasite virulence in mice 
(Saeij et al., 2006; Taylor et al., 2006). Type I T. gondii secretes a catalytically active form of ROP18 that phosphorylates IRGs at two threonine residues in the nucleotide-binding domain (Fentress et al., 2010; Steinfeldt et al., 2010) (Figure 3B). As a result, the GTPase function of IRGs is inhibited and their oligomerization and loading into the PVM are impaired (Fentress et al., 2010; Steinfeldt et al., 2010). The ability of ROP18 to phosphorylate IRGs is dependent on the presence of virulent alleles of ROP5. ROP5 are a group of catalytically inactive kinases (pseudokinases) that control parasite virulence in mice (Behnke et al., 2011; Reese et al., 2011). ROP5 proteins bind a conserved surface of IRG and promote that IRG remain in an inactive GDP-bound conformation (Fleckenstein et al., 2012; Reese et al., 2014). As a result, GTP-dependent activation of IRG is prevented, and threonines in the nucleotide-binding domain become exposed, enabling their phosphorylation by ROP18 and permanent inactivation of IRG (Fleckenstein et al., 2012; Reese et al., 2014). Thus, ROP5 appears to act as an allosteric regulator of ROP18 (Reese et al., 2014) and is required for the catalytic activity of ROP18 (Behnke et al., 2012). Indeed, virulent forms of both ROP5 and ROP18 are required to prevent IRG recruitment to the PVM. ROP18 and ROP5 largely explain the differences in virulence in mice among type I, II, and III strains (Saeij et al., 2006; Taylor et al., 2006). Despite encoding ROP18 that is likely catalytically active, type II strains cannot prevent IRG recruitment because they carry alleles of ROP5 that do not assist IRG phosphorylation by ROP18. In addition, type III strains carry a high-virulence allele of ROP5 but are avirulent because of their minimal expression of ROP18. The allelic combination of ROP18 and ROP5 genes also determines the virulence of atypical strains of T. gondii (Niedelman et al., 2012).

In addition to ROP18 and ROP5, ROP17 also contributes to T. gondii virulence in mice (Etheridge et al., 2014). ROP17 associates with ROP5 and phosphorylates threonine residues of

\section{REFERENCES}

Anantharaman, V., Iyer, L. M., Balaji, S., and Aravind, L. (2007). Adhesion molecules and other secreted host-interaction determinants in Apicomplexa: insights from comparative geneomics. Int. Rev. Cytol. 262, 1-74. doi: 10.1016/S0074-7696(07)62001-4

Andrade, R. M., Wessendarp, M., Gubbels, M. J., Striepen, B., and Subauste, C. S. (2006). CD40 induces macrophage anti-Toxoplasma gondii activity by triggering autophagy-dependent fusion of pathogen-containing vacuoles and lysosomes. J. Clin. Invest. 116, 2366-2377. doi: 10.1172/JCI 28796

Behnke, M. S., Fentress, S. J., Mashayekhi, M., Li, L. X., Taylor, G. A., and Sibley, L. D. (2012). The polymorphic pseudokinase ROP5 controls virulence in Toxoplasma gondii by regulating the active kinase ROP18. PLoS Pathog. 8:e1002992. doi: 10.1371/journal.ppat.1002992

Behnke, M. S., Khan, A., Wootton, J. C., Dubey, J. P., Tang, K., and Sibley, L. D. (2011). Virulence differences in Toxoplasma mediated by amplification of a family of polymorphic pseudokinases. Proc. Natl. Acad. Sci. U.S.A. 108, 9631-9636. doi: 10.1073/pnas.1015338108

Bekpen, C., Hunn, J. P., Rohde, C., Parvanova, I., Guethlein, L., Dunn, D. M., et al. (2005). The interferon-inducible p47 (IRG) GTPases in vertebrates: loss of the cell autonomous resistance mechanism in the human lineage. Genome Biol. 6:R92. doi: 10.1186/gb-2005-6-11-r92
IRG (Etheridge et al., 2014). However, in contrast to ROP18, the in vitro activity of ROP17 does not require ROP5 (Etheridge et al., 2014). Finally, the dense granule protein GRA7 is another component of the ROP18-ROP5 complex and modulates IRG recruitment to the PVM (Hermanns et al., 2016) (Figure 3B). GRA7 appears to associate with ROP5 and functions by allowing efficient ROP18 kinase activity (Hermanns et al., 2016).

In summary, important advances have been achieved in our understanding of how autophagy proteins and autophagy attack $T$. gondii-containing vacuoles within host cells. Given that maintaining the integrity of this niche is essential to parasite survival, it is not surprising that $T$. gondii utilizes various strategies to counteract the effects of autophagy proteins and autophagy. Pharmacologic approaches to enhance autophagy for therapeutic purposes may be complicated by the homeostatic role of autophagy in various cellular processes, the complexity of autophagy cascades, and the specificity of pharmacologic agents. Strategies to prevent T. gondii from blocking autophagic targeting may represent a more feasible avenue to develop novel ancillary approaches to improve the treatment of toxoplasmosis.

\section{AUTHOR CONTRIBUTIONS}

The author confirms being the sole contributor of this work and has approved it for publication.

\section{FUNDING}

\section{CS is funded by NIH-R01 EY018341 and NIH-R01 EY019250.}

\section{ACKNOWLEDGMENTS}

The author thanks all the members of the Subauste lab for their feedback on this manuscript.

Besteiro, S., Dubremetz, J. F., and Lebrun, M. (2011). The moving junction of apicomplexan parasites: a key structure for invasion. Cell. Microbiol. 13, 797-805. doi: 10.1111/j.1462-5822.2011.01597.x

Biscardi, J. S., Maa, M. C., Tice, D. A., Cox, M. E., Leu, T. H., and Parsons, J. T. (1999). c-Src-mediated phosphorylation of the epidermal growth factor receptor on Tyr845 and Tyr1101 is associated with modulation of receptor function. J. Biol. Chem. 274, 8335-8343. doi: 10.1074/jbc.274.12.8335

Bradley, P. J., and Sibley, L. D. (2007). Rhoptries: an arsenal of secreted virulence factors. Curr. Opin. Microbiol. 10, 582-587. doi: 10.1016/j.mib.2007.09.013

Carruthers, V. B., and Tomley, F. M. (2008). Receptor-ligand interaction and invasion: microneme proteins in apicomplexans. Subcell. Biochem. 47, 33-45. doi: 10.1007/978-0-387-78267-6_2

Cerede, O., Dubremetz, J. F., Soete, M., Deslee, D., Vial, H., Bout, D., et al. (2005). Synergistic role of micronemal proteins in Toxoplasma gondii virulence. J. Exp. Med. 201, 453-463. doi: 10.1084/jem.20041672

Chan, E. Y., Longatti, A., Mcknight, N. C., and Tooze, S. A. (2009). Kinaseinactivated ULK proteins inhibit autophagy via their conserved C-terminal domains using an Atg13-independent mechanism. Mol. Cell. Biol. 29, 157-171. doi: 10.1128/MCB.01082-08

Chang, Y. Y., Juhasz, G., Goraksha-Hicks, P., Arsham, A. M., Mallin, D. R., Muller, L. K., et al. (2009). Nutrient-dependent regulation of autophagy through the target of rapamycin pathway. Biochem. Soc. Trans. 37, 232-236. doi: 10.1042/BST0370232 
Chauhan, S., Mandell, M. A., and Deretic, V. (2015). IRGM governs the core autophagy machinery to conduct antimicrobial defense. Mol. Cell 58, 507-521. doi: 10.1016/j.molcel.2015.03.020

Choi, J., Park, S., Biering, S. B., Selleck, E., Liu, C. Y., Zhang, X., et al. (2014). The parasitophorous vacuole membrane of Toxoplasma gondii is targeted for disruption by ubiquitin-like conjugation systems of autophagy. Immunity 40, 924-935. doi: 10.1016/j.immuni.2014.05.006

Clough, B., Wright, J. D., Pereira, P. M., Hirst, E. M., Johnston, A. C., Henriques, R., et al. (2016). K63-Linked ubiquitination targets Toxoplasma gondii for endolysosomal destruction in IFN-gamma-stimulated human cells. PLoS Pathog. 12:e1006027. doi: 10.1371/journal.ppat.1006027

Coppens, I., Dunn, J. D., Romano, J. D., Pypaert, M., Zhang, H., Boothroyd, J. C., et al. (2006). Toxoplasma gondii sequesters lysosomes from mammalian hosts in the vacuolar space. Cell 125, 261-274. doi: 10.1016/j.cell.2006.01.056

Courret, N., Darche, S., Sonigo, P., Milon, G., Buzoni-Gatel, D., and Tardieux, I. (2006). CD11c- and CD11b-expressing mouse leukocytes transport single Toxoplasma gondii tachyzoites to the brain. Blood 107, 309-316. doi: 10.1182/blood-2005-02-0666

Egan, D. F., Shackelford, D. B., Mihaylova, M. M., Gelino, S., Kohnz, R. A., Mair, W., et al. (2011). Phosphorylation of ULK1 (hATG1) by AMP-activated protein kinase connects energy sensing to mitophagy. Science 331, 456-461. doi: 10.1126/science.1196371

Etheridge, R. D., Alaganan, A., Tang, K., Lou, H. J., Turk, B. E., and Sibley, L. D. (2014). The Toxoplasma pseudokinase ROP5 forms complexes with ROP18 and ROP17 kinases that synergize to control acute virulence in mice. Cell Host Microbe 15, 537-550. doi: 10.1016/j.chom.2014.04.002

Fentress, S. J., Behnke, M. S., Dunay, I. R., Mashayekhi, M., Rommereim, L. M., Fox, B. A., et al. (2010). Phosphorylation of immunity-related GTPases by a Toxoplasma gondii-secreted kinase promotes macrophage survival and virulence. Cell Host Microbe 8, 484-495. doi: 10.1016/j.chom.2010.11.005

Fleckenstein, M. C., Reese, M. L., Konen-Waisman, S., Boothroyd, J. C., Howard, J. C., and Steinfeldt, T. (2012). A Toxoplasma gondii pseudokinase inhibits host IRG resistance proteins. PLoS Biol. 10:e1001358. doi: 10.1371/journal.pbio. 1001358

Gade, P., Ramachandran, G., Maachani, U. B., Rizzo, M. A., Okada, T., Prywes, R., et al. (2012). An IFN-gamma-stimulated ATF6-C/EBP-beta-signaling pathway critical for the expression of Death Associated Protein Kinase 1 and induction of autophagy. Proc. Natl. Acad. Sci. U.S.A. 109, 10316-10321. doi: 10.1073/pnas.1119273109

Galluzzi, L., Baehrecke, E. H., Ballabio, A., Boya, P., Bravo-San Pedro, J. M., Cecconi, F., et al. (2017). Molecular definitions of autophagy and related processes. EMBO J. 36, 1811-1836. doi: 10.15252/embj.2017 96697

Gutierrez, M. G., Munafo, D. B., Beron, W., and Colombo, M. C. (2004). Rab7 is required for the normal progression of the autophagic pathway in mammalian cells. J. Cell Sci. 117, 2687-2697. doi: 10.1242/jcs.01114

Haldar, A. K., Foltz, C., Finethy, R., Piro, A. S., Feeley, E. M., Pilla-Moffett, D. M., et al. (2015). Ubiquitin systems mark pathogen-containing vacuoles as targets for host defense by guanylate binding proteins. Proc. Natl. Acad. Sci. U.S.A. 112, E5628-E5637. doi: 10.1073/pnas.1515966112

Haldar, A. K., Piro, A. S., Pilla, D. M., Yamamoto, M., and Coers, J. (2014). The E2-like conjugation enzyme Atg3 promotes binding of IRG and Gbp proteins to Chlamydia- and Toxoplasma-containing vacuoles and host resistance. PLoS ONE 9:e86684. doi: 10.1371/journal.pone.0086684

Hermanns, T., Muller, U. B., Konen-Waisman, S., Howard, J. C., and Steinfeldt, T. (2016). The Toxoplasma gondii rhoptry protein ROP18 is an Irga6-specific kinase and regulated by the dense granule protein GRA7. Cell. Microbiol. 18, 244-259. doi: $10.1111 / \mathrm{cmi} .12499$

Huynh, M.-H., and Carruthers, V. B. (2006). Toxoplasma MIC2 is a major determinant of invasion and virulence. PLoS Pathog. 2:e84. doi: 10.1371/journal.ppat.0020084

Itakura, E., and Mizushima, N. (2010). Characterization of autophagosome formation site by a hierarchical analysis of mammalian Atg proteins. Autophagy 6, 764-776. doi: 10.4161/auto.6.6.12709

Kabeya, Y., Mizushima, N., Ueno, T., Yamamoto, A., Kirisako, T., Noda, T., et al. (2000). LC3, a mammalian homologue of yeast Apg8p, is localized in autophagosome membranes after processing. EMBO J. 19, 5720-5728. doi: $10.1093 / \mathrm{emboj} / 19.21 .5720$
Kessler, H., Hern-Gotz, A., Hegge, S., Rauch, M., Soldati-Favre, D., Frischknecht, F., et al. (2008). Micronem protein 8 - a new essential invasion factor in Toxoplasma gondii. J. Cell Sci. 121, 947-956. doi: 10.1242/jcs.022350

Khaminets, A., Hunn, J. P., Konen-Waisman, S., Zhao, Y. O., Preukschat, D., Coers, J., et al. (2010). Coordinated loading of IRG resistance GTPases on to the Toxoplasma gondii parasitophorous vacuole. Cell. Microbiol. 12, 939-961. doi: 10.1111/j.1462-5822.2010.01443.x

Kim, J., Kundu, M., Viollet, B., and Guan, K. L. (2011). AMPK and mTOR regulate autophagy through direct phosphorylation of Ulk1. Nat. Cell Biol. 13, 132-141. doi: $10.1038 /$ ncb2152

Kim, L., and Denkers, E. Y. (2006). Toxoplasma gondii triggers Gi-dependent PI3kinase signaling required for inhibition of host cell apoptosis. J. Cell Sci. 119, 2119-2126. doi: 10.1242/jcs.02934

Klionsky, D. J., and Emr, S. D. (2000). Autophagy as a regulated pathway of cellular degradation. Science 290, 1717-1721. doi: 10.1126/science.290.5497.1717

Konradt, C., Ueno, N., Christian, D. A., Delong, J. H., Pritchard, G. H., Herz, J., et al. (2016). Endothelial cells are a replicative niche for entry of Toxoplasma gondii to the central nervous system. Nat. Microbiol. 1:16001. doi: 10.1038/nmicrobiol.2016.1

Kravets, E., Degrandi, D., Ma, Q., Peulen, T. O., Klumpers, V., Felekyan, S., et al. (2016). Guanylate binding proteins directly attack Toxoplasma gondii via supramolecular complexes. Elife 5:e11479. doi: 10.7554/eLife.11479

Latre De Late, P., Pineda, M., Harnett, M., Harnett, W., Besteiro, S., and Langsley, G. (2017). Apicomplexan autophagy and modulation of autophagy in parasiteinfected host cells. Biomed. J. 40, 23-30. doi: 10.1016/j.bj.2017.01.001

Levine, B., Mizushima, N., and Virgin, H. W. (2011). Autophagy in immunity and inflammation. Nature 469, 323-335. doi: 10.1038/nature09782

Liang, X. H., Jackson, S., Seaman, M., Brown, K. D., Kempkes, B., Hibshoosh, H., et al. (1999). Induction of autophagy and inhibition of tumorigenesis by beclin 1. Nature 402, 672-676. doi: 10.1038/45257

Ling, Y. M., Shaw, M. H., Ayala, C., Coppens, I., Taylor, G. A., Ferguson, D. J. P., et al. (2006). Vacuolar and plasma membrane stripping and autophagic elimination of Toxoplasma gondii in primed effector macrophages. J. Exp. Med. 203, 2063-2071. doi: 10.1084/jem.20061318

Liu, E., Lopez Corcino, Y., Portillo, J. A. C., Miao, Y., and Subauste, C.S. (2016). Identification of signaling pathways by which CD40 stimulates autophagy and anti-microbial activity against Toxoplasma gondii in macrophages. Infect. Immun. 84, 2616-2626. doi: 10.1128/IAI.00101-16

Liu, E., Van Grol, J., and Subauste, C. S. (2015). Atg5 but not Atg7 in dendritic cells enhance IL- 2 and IFN- $\gamma$ production by Toxoplasma gondii-reactive CD4+ T cells. Microbes Infect. 17, 275-284. doi: 10.1016/j.micinf.2014.12.008

Lopez Corcino, Y., Portillo, J.-A. C., and Subauste, C. S. (2019). Epidermal growth factor receptor promotes cerebral and retinal invasion by Toxoplasma gondii. Sci. Rep. 9:669. doi: 10.1038/s41598-018-36724-2

Mack, H. I., Zheng, B., Asara, J. M., and Thomas, S. M. (2012). AMPKdependent phosphorylation of ULK1 regulates ATG9 localization. Autophagy 8, 1197-1214. doi: 10.4161/auto.20586

Martens, S., Parvanova, I., Zerrahn, J., Griffiths, G., Schell, G., Reichmann, G., et al. (2005). Disruption of Toxoplasma gondii parasitophorous vacuoles by the mouse p47-resistance GTPases. PLoS Pathog. 1:e24. doi: 10.1371/journal.ppat.0010024

Martinez, J., Malireddi, R. K., Lu, Q., Cunha, L. D., Pelletier, S., Gingras, S., et al. (2015). Molecular characterization of LC3-associated phagocytosis reveals distinct roles for Rubicon, NOX2 and autophagy proteins. Nat. Cell Biol. 17, 893-906. doi: 10.1038/ncb3192

Matsunaga, K., Saitoh, T., Tabata, K., Omori, H., Satoh, T., Kurotori, N., et al. (2009). Two Beclin 1-binding proteins, Atg14L and Rubicon, reciprocally regulate autophagy at different stages. Nat. Cell Biol. 11, 385-396. doi: $10.1038 /$ ncb1846

Matsuzawa, T., Kim, B. H., Shenoy, A. R., Kamitani, S., Miyake, M., and Macmicking, J. D. (2012). IFN-gamma elicits macrophage autophagy via the p38 MAPK signaling pathway. J. Immunol. 189, 813-818. doi: 10.4049/jimmunol.1102041

Meissner, M., Reiss, M., Viebig, N., Carruthers, V. B., Toursel, C., Tomavo, S., et al. (2002). A family of transmembrane microneme proteins of Toxoplasma gondii contain EGF-like domains and function as escorters. J. Cell Sci. 115, 563-574.

Menon, S., Dibble, C. C., Talbott, G., Hoxhaj, G., Valvezan, A. J., Takahashi, H., et al. (2014). Spatial control of the TSC complex integrates insulin 
and nutrient regulation of mTORC1 at the lysosome. Cell 156, 771-785. doi: 10.1016/j.cell.2013.11.049

Mizushima, N., Noda, T., Yoshimori, T., Tanaka, Y., Ishii, T., George, M. D., et al. (1998). A protein conjugation system essential for autophagy. Nature 395, 395-398. doi: 10.1038/26506

Mizushima, N., Yoshimori, T., and Ohsumi, Y. (2010). The role of Atg proteins in autophagosome formation. Annu. Rev. Cell Dev. Biol. 27, 107-132. doi: 10.1146/annurev-cellbio-092910-154005

Mordue, D. G., Desai, N., Dustin, M., and Sibley, L. D. (1999). Invasion by Toxoplasma gondii establishes a moving junction that selectively excludes host cell plasma membrane proteins on the basis of their membrane anchoring. J. Exp. Med. 190, 1783-1792. doi: 10.1084/jem.190.12.1783

Moro, L., Dolce, L., Cabodi, S., Bergatto, E., Boeri Erba, E., Smeriglio, M., et al. (2002). Integrin-induces epidermal growth factor (EGF) receptor activation requires c-Src and p130Cas and leads to phosphorylation of specific EGF receptor tyrosines. J. Biol. Chem. 277, 9405-9414. doi: 10.1074/jbc.M109101200

Muniz-Feliciano, L., Van Grol, J., Portillo, J.-A. C., Liew, L., Liu, B., Carlin, C. R., et al. (2013). Toxoplasma gondii-induced activation of EGFR prevents autophagy protein-mediated killing of the parasite. PLoS Pathog. 9:e1003809. doi: 10.1371/journal.ppat.1003809

Nascimbeni, A. C., Codogno, P., and Morel, E. (2017). Phosphatidylinositol-3phosphate in the regulation of autophagy membrane dynamics. FEBS J. 284, 1267-1278. doi: 10.1111/febs.13987

Niedelman, W., Gold, D. A., Rosowski, E. E., Sprokholt, J. K., Lim, D., Farid Arenas, A., et al. (2012). The rhoptry proteins ROP18 and ROP5 mediate Toxoplasma gondii evasion of the murine, but not the human, IFN-gamma response. PLoS Pathog. 8:e1002784. doi: 10.1371/journal.ppat.1002784

Niedelman, W., Sprokholt, J. K., Clough, B., Frickel, E. M., and Saeij, J. P. (2013). Cell death of gamma interferon-stimulated human fibroblasts upon Toxoplasma gondii infection induces early parasite egress and limits parasite replication. Infect. Immun. 81, 4341-4349. doi: 10.1128/IAI.00416-13

Ogolla, P., Portillo, J.-A. C., White, C. L., Patel, K., Lamb, B., Sen, G. C., et al. (2013). The protein kinase double-stranded RNA-dependent (PKR) enhances protection against disease cause by a non-viral pathogen. PLoS Pathog. 9:e100557. doi: 10.1371/journal.ppat.1003557

Ohshima, J., Lee, Y., Sasai, M., Saitoh, T., Su Ma, J., Kamiyama, N., et al. (2014). Role of mouse and human autophagy proteins in IFN-gamma-induced cellautonomous responses against Toxoplasma gondii. J. Immunol. 192, 3328-3335. doi: $10.4049 /$ jimmunol.1302822

Papinski, D., Schuschnig, M., Reiter, W., Wilhelm, L., Barnes, C. A., Maiolica, A., et al. (2014). Early steps in autophagy depend on direct phosphorylation of Atg9 by the Atg1 kinase. Mol. Cell 53, 471-483. doi: 10.1016/j.molcel.2013.12.011

Park, S., Choi, J., Biering, S. B., Dominici, E., Williams, L. E., and Hwang, S. (2016). Targeting by AutophaGy proteins (TAG): targeting of IFNG-inducible GTPases to membranes by the LC3 conjugation system of autophagy. Autophagy 12, 1153-1167. doi: 10.1080/15548627.2016.1178447

Pattingre, S., Tassa, A., Qu, X., Garuti, R., Liang, X. H., Mizushima, N., et al. (2005). Bcl-2 antiapoptotic proteins inhibit Beclin 1-dependent autophagy. Cell 122, 927-939. doi: 10.1016/j.cell.2005.07.002

Pernas, L., Bean, C., Boothroyd, J. C., and Scorrano, L. (2018). Mitochondria restrict growth of the intracellular parasite Toxoplasma gondii by limiting its uptake of fatty acids. Cell Metab. 27, 886-897 e884. doi: 10.1016/j.cmet.2018.02.018

Pfefferkorn, E. R. (1984). Interferon- $\gamma$ blocks the growth of Toxoplasma gondii in human fibroblasts by inducing the host cell to degrade tryptophan. Proc. Natl. Acad. Sci. U.S.A 81, 908-912. doi: 10.1073/pnas.81.3.908

Portillo, J.-A. C., Okenka, G., Reed, E., Subauste, A., Van Grol, J., Gentil, K., et al. (2010). The CD40-autophagy pathway is needed for host protection despite IFN- $\gamma$-dependent immunity and CD40 induces autophagy via control of p21 levels. PLoS ONE 5:e14472. doi: 10.1371/journal.pone.0014472

Portillo, J. C., Muniz-Feliciano, L., Lopez Corcino, Y., Lee, S. J., Van Grol, J., Parsons, S. J., et al. (2017). Toxoplasma gondii induces FAKSrc-STAT3 signaling during infection of host cells that prevents parasite targeting by autophagy. PLoS Pathog. 13:e1006671. doi: 10.1371/journal.ppat.10 06671

Purba, E. R., Saita, E. I., and Maruyama, I. N. (2017). Activation of the EGF receptor by ligand binding and oncogenic mutations: the "Rotation Model". Cells 6:E13. doi: $10.3390 /$ cells6020013
Reese, M. L., Shah, N., and Boothroyd, J. C. (2014). The Toxoplasma pseudokinase ROP5 is an allosteric inhibitor of the immunity-related GTPases. J. Biol. Chem. 289, 27849-27858. doi: 10.1074/jbc.M114.567057

Reese, M. L., Zeiner, G. M., Saeij, J. P., Boothroyd, J. C., and Boyle, J. P. (2011). Polymorphic family of injected pseudokinases is paramount in Toxoplasma virulence. Proc. Natl. Acad. Sci. U.S.A. 108, 9625-9630. doi: $10.1073 /$ pnas. 1015980108

Reichmann, G., Walker, W., Villegas, E. N., Craig, L., Cai, G., Alexander, J., et al. (2000). The CD40/CD40 ligand interaction is required for resistance to toxoplasmic encephalitis. Infect. Immun. 68, 1312-1318. doi: 10.1128/IAI.68.3.1312-1318.2000

Russell, R. C., Tian, Y., Yuan, H., Park, H. W., Chang, Y. Y., Kim, J., et al. (2013). ULK1 induces autophagy by phosphorylating Beclin-1 and activating VPS34 lipid kinase. Nat. Cell Biol. 15, 741-750. doi: 10.1038/ncb2757

Saeij, J. P., Boyle, J. P., Coller, S., Taylor, S., Sibley, L. D., Brooke-Powell, E. T., et al. (2006). Polymorphic secreted kinases are key virulence factors in toxoplasmosis. Science 314, 1780-1783. doi: 10.1126/science.1133690

Sanjuan, M. A., Dillo, C. P., Tait, S. W. G., Moshiach, S., Dorsey, F., Connell, S., et al. (2007). Toll-like receptor signalling in macrophages links the autophagy pathway to phagocytosis. Nature 450, 1253-1257. doi: 10.1038/nature06421

Santos, J. M., and Soldati-Favre, D. (2011). Invasion factors are coupled to key signalling events leading to the establishment of infection in apicomplexan parasites. Cell. Microbiol. 13, 787-796. doi: 10.1111/j.1462-5822.2011.01585.x

Sasai, M., Sakaguchi, N., Ma, J. S., Nakamura, S., Kawabata, T., Bando, H., et al. (2017). Essential role for GABARAP autophagy proteins in interferoninducible GTPase-mediated host defense. Nat. Immunol. 18, 899-910. doi: 10.1038/ni.3767

Selleck, E. M., Fentress, S. J., Beatty, W. L., Degrnadi, D., Pfeffer, K., Virgin, H. W., et al. (2013). Guanylate-binding protein 1 (Gbp1) contributes to cellautonomous immunity against Toxoplasma gondii. PLoS Pathog. 9:e1003320. doi: 10.1371/journal.ppat.1003320

Selleck, E. M., Orchard, R. C., Lassen, K. G., Beatty, W. L., Xavier, R. J., Levine, B., et al. (2015). A Noncanonical autophagy pathway restricts Toxoplasma gondii growth in a strain-specific manner in IFN-gamma-activated human cells. MBio 6, e01157-e01115. doi: 10.1128/mBio.01157-15

Sheiner, L., Santos, J. M., Klages, N., Parussini, F., Jemmely, N., Friedrich, N., et al. (2010). Toxoplasma gondii transmembrane microneme proteins and their modular design. Mol. Microbiol. 77, 912-929. doi: 10.1111/j.1365-2958.2010.07255.x

Shen, S., Niso-Santano, M., Adjemian, S., Takehara, T., Malik, S. A., Minoux, H., et al. (2012). Cytoplasmic STAT3 represses autophagy by inhibiting PKR activity. Mol. Cell 48, 667-680. doi: 10.1016/j.molcel.2012.09.013

Shi, C.-S., and Kehrl, J. H. (2010). TRAF6 and A20 regulate lysine 63-linked ubiquitination of Beclin-1 to control TLR4-induced autophagy. Sci. Signal. 3:ra42. doi: 10.1126/scisignal.2000751

Sibley, L. D. (2011). Invasion and intracellular survival by protozoan parasites. Immunol. Rev. 240, 72-91. doi: 10.1111/j.1600-065X.2010.00990.x

Sobolewska, A., Gajewska, M., Zarzynska, J., Gajkowska, B., and Motyl, T. (2009). IGF-I, EGF, and sex steroids regulate autophagy in bovine mammary epithelial cells via the mTOR pathway. Eur. J. Cell Biol. 88, 117-130. doi: 10.1016/j.ejcb.2008.09.004

Soldati-Favre, D. (2008). Molecular dissection of host cell invasion by the apicomplexans: the glideosome. Parasite 15, 197-205. doi: 10.1051/parasite/2008153197

Steinfeldt, T., Konen-Waisman, S., Tong, L., Pawlowski, N., Lamkemeyer, T., Sibley, L. D., et al. (2010). Phosphorylation of mouse immunity-related GTPase (IRG) resistnace proteins is an evasion strategy for virulent Toxoplasma gondii. PLoS Biol. 8:e1000576. doi: 10.1371/journal.pbio.1000576

Stolz, A., Ernst, A., and Dikic, I. (2014). Cargo recognition and trafficking in selective autophagy. Nat. Cell Biol. 16, 495-501. doi: 10.1038/ncb2979

Subauste, C. S., Andrade, R. M., and Wessendarp, M. (2007). CD40-TRAF6 and autophagy-dependent anti-microbial activity in macrophages. Autophagy 3, 245-248. doi: 10.4161/auto.3717

Subauste, C. S., Wessendarp, M., Sorensen, R. U., and Leiva, L. (1999). CD40-CD40 ligand interaction is central to cell-mediated immunity against Toxoplasma gondii: patients with hyper IgM syndrome have a defective type-1 immune response which can be restored by soluble CD40L trimer. J. Immunol. 162, $6690-6700$. 
Subramani, S., and Malhotra, V. (2013). Non-autophagic roles of autophagyrelated proteins. EMBO Rep. 14, 143-151. doi: 10.1038/embor.2012.220

Sun, Q., Fan, W., Chen, K., Ding, X., Chen, S., and Zhong, Q. (2008). Identification of Barkor as a mammalian autophagy-specific factor for Beclin 1 and class III phosphatidylinositol 3-kinase. Proc. Natl. Acad. Sci. U.S.A. 105, 19211-19216. doi: 10.1073/pnas.0810452105

Talloczy, Z., Jiang, W., Virgin, H. W., Leib, D. A., Scheuner, D., Kaufman, R. J., et al. (2002). Regulation of starvation- and virus-induced autophagy by the eIF2 $\alpha$ signaling pathway. Proc. Natl. Acad. Sci. U.S.A. 99, 190-195. doi: $10.1073 /$ pnas. 012485299

Talloczy, Z., Virgin, H. W., and Levine, B. (2006). PKR-dependent autophagic degradation of herpes simplex virus type 1. Autophagy 2, 24-29. doi: 10.4161/auto.2176

Taylor, S., Barragan, A., Su, C., Fux, B., Fentress, S. J., Tang, K., et al. (2006). A secreted serine-threonine kinase determines virulence in the eukaryotic pathogen Toxoplasma gondii. Science 314, 1776-1780. doi: $10.1126 /$ science. 1133643

Tomley, F. M., and Soldati, D. S. (2001). Mix and match modules: structure and function of microneme proteins in apicomplexan parasites. Trends Parasitol. 17, 81-88. doi: 10.1016/S1471-4922(00)01761-X

Van Grol, J., Muniz-Feliciano, L., Portillo, J. A. C., Bonilha, V. L., and Subauste, C. S. (2013). CD40 induces anti-Toxoplasma gondii activity in nonhematopoietic cells dependent on autophagy proteins. Infect. Immun. 81, 2002-2011. doi: 10.1128/IAI.01145-12

Van Grol, J., Subauste, M. C., Andrade, R. M., Fujinaga, K., Nelson, J. A., and Subauste, C. S. (2010). HIV-1 inhibits autophagy in bystander macrophages/monocytic cells through Src-Akt and STAT3. PLoS ONE 5:e11733. doi: 10.1371/journal.pone.0011733

Van Kooten, C., and Banchereau, J. (2000). CD40-CD40 ligand. J. Leuk. Biol. 67, 2-17. doi: $10.1002 / \mathrm{jlb} .67 .1 .2$

Wang, Y., Weiss, L. M., and Orlofsky, A. (2009). Host cell autophagy is induced by Toxoplasma gondii and contributes to parasite growth. J. Biol. Chem. 284, 1694-1701. doi: 10.1074/jbc.M807890200

Wei, Y., Pattingre, S., Sinha, S., Bassik, M., and Levine, B. (2008). JNK1-mediated phosphorylation of $\mathrm{Bcl}-2$ regulates starvation-induced autophagy. Mol. Cell 30, 678-688. doi: 10.1016/j.molcel.2008.06.001
Wild, P., Mcewan, D. G., and Dikic, I. (2014). The LC3 interactome at a glance. J. Cell Sci. 127, 3-9. doi: 10.1242/jcs.140426

Woodman, J. P., Dimier, I. H., and Bout, D. T. (1991). Human endothelial cells are activated by IFN- $\gamma$ to inhibit Toxoplasma gondii replication. J. Immunol. 147, 2019-2023.

Yang, Z., Ahn, H. J., and Nam, H. W. (2014). Gefitinib inhibits the growth of Toxoplasma gondii in HeLa cells. Korean J. Parasitol. 52, 439-441. doi: $10.3347 / \mathrm{kjp} .2014 .52 .4 .439$

Yarden, Y., and Sliwkowski, M. X. (2001). Untangling the ErbB signalling network. Nat. Rev. Mol. Cell Biol. 2, 127-137. doi: 10.1038/35052073

Yoshimori, T. (2004). Autophagy: a regulated bulk degradation process inside cells. Biochem. Biophys. Res. Comm. 313, 453-458. doi: 10.1016/j.bbrc.2003. 07.023

Zhao, Y., Ferguson, D. J., Wilson, D. C., Howard, J. C., Sibley, L. D., and Yap, G. S. (2009). Virulent Toxoplasma gondii evade immunity-related GTPasemediated parasite vacuole disruption within primed macrophages. J. Immunol. 182, 3775-3781. doi: 10.4049/jimmunol.0804190

Zhao, Y., Wilson, D., Matthews, S., and Yap, G. S. (2007). Rapid elimination of Toxoplasma gondii by gamma interferon-primed mouse macrophages is independent of CD40 signaling. Infect. Immun. 75, 4799-4803. doi: 10.1128/IAI.00738-07

Zhao, Z., Fux, B., Goodwin, M., Dunay, I. R., Strong, D., Miller, B. C., et al. (2008). Autophagosome-independent essential function for the autophagy protein Atg5 in cellular immunity to intracellular pathogens. Cell Host Microbe 4, 458-469. doi: 10.1016/j.chom.2008.10.003

Conflict of Interest Statement: The author declares that the research was conducted in the absence of any commercial or financial relationships that could be construed as a potential conflict of interest.

Copyright $\odot 2019$ Subauste. This is an open-access article distributed under the terms of the Creative Commons Attribution License (CC BY). The use, distribution or reproduction in other forums is permitted, provided the original author(s) and the copyright owner(s) are credited and that the original publication in this journal is cited, in accordance with accepted academic practice. No use, distribution or reproduction is permitted which does not comply with these terms. 